\title{
Comparative Clustering Approach Intended for Evaluating SaaS
}

\author{
Dhanamma Jagli \\ Research Scholar, JNTUCE \\ Hyderabad, and Assistant \\ Professor, VESIT, University of \\ Mumbai, India.
}

\author{
Seema Purohit, PhD \\ Research Guide, JNTUCE \\ Hyderabad and Kirti College, \\ University of Mumbai, India.
}

\author{
N. Subhash Chandra, PhD \\ Research Guide, JNTUCE \\ Hyderabad, and Professor, \\ HITS, JNTU Hyderabad, India.
}

\begin{abstract}
The Cloud computing is key computing and playing an important role to share many resources. The Software as a service (SaaS) service model is giving more benefits to the end user. Any user wants to use the software as a service, will not install any software locally rather they can access any application/software as assertive via the internet just by login to the system. For every service user, selecting the suitable one became a difficult task. Hence in this paper providing various data mining clustering algorithms and their comparison based AWS data sets collected. The goal of this research is to provide a decision-making system with optimal solutions to cloud service users and providers to select/provide potential software services and afford according to specified requirements quickly and easily.
\end{abstract}

\section{Keywords}

SaaS, K-means Clustering, Hierarchical Clustering, BiCluster, Cloud Computing

\section{INTRODUCTION}

Cloud Computing is a general term used to describe a new class of network-based computing that takes place over the Internet, basically a step on from Utility Computing a collection/group of integrated and networked hardware, software and Internet infrastructure (called a platform).Using the Internet for communication and transport provides hardware, software and networking services to clients These platforms hide the complexity and details of the underlying infrastructure from users and applications by providing a very simple graphical interface or API. The cloud computing has been growing as an essential and leading computing platform for sharing resources.

It is a style of computing in which resources are provided "as a service" to users who need not have knowledge of, expertise in, or control over the infrastructure. Pay for use and as needed, elastic scale up and down in capacity and functionalities. The hardware and software services are available to general public, enterprises, corporations and businesses markets. Software as a service (SaaS) is referred as on-demand software supplied by service providers. The SaaS is a model provides several uses to service consumers without installing any application locally. SaaS is commonly utilised and provides many benefits to service users. It is essential to evaluate the potential quality of SaaS, not only to the service users but also to the service providers. IaaS delivers computer infrastructure, typically a platform virtualization environment, as a service. Rather than purchasing servers, software, datacenter space or network equipment, clients instead buy those resources as a fully outsourced service. PaaS delivers a computing platform where the developers can develop their own applications. SaaS is a model of software deployment where the software applications are provided to the customers as a service. SaaS is a model of software deployment where an application is hosted as a service provided to customers across the Internet. SaaS alleviates the burden of software maintenance/support users relinquish control over software versions and requirements.

The Cloud computing is playing a vital role as a backbone component of the Internet of Things (IoT).Pay for use concept is very attractive, hence many organisations are adopting the SaaS model drastically. Even though, each customer is unique and leads to unique variation in the requirements of the software. In order to discriminate between service providers from various competitors and other cloud service vendors, there should be some measure to know superiority of services.

More and more SaaS services are emerging, how to select qualified service is a key challenge for customers. Any standard quality model can be used to represent measure and compare the quality of the Software services on the cloud. Present existed quality models are not sufficient to evaluate SaaS selection on the cloud due to its tremendous increase in the use.

\section{LITERATURE SURVEY}

The work has been done many researchers towards SaaS evaluation was comparatively very less till 2005.after 2005 the research work contributed towards SaaS Evaluation is studied thoroughly and analysed. Literature Survey had been done according to basic SaaS features, other quality attributes, and quality metrics and other parameters which are involved in the process of quality evaluation of the SaaS. All Quality models are working based on quality attributes and quality metrics of the software. No quality model is focusing on all of the quality attributes of the software. It is concluded that same quality attributes of conventional software are not enough to evaluate software services on the cloud. Basic features of SaaS are identified as important parameters to evaluate the Quality of SaaS on the cloud. It has been observed that very few researchers had focused on Basic features of SaaS, even though they are very crucial. Many other individual attributes are involved in the process of quality evaluation of SaaS but not considered all the time. It is also concluded that few researchers have been using quality metrics and their validation. Very less number of quality models are verified and compared with a standard quality model for quality evaluation of SaaS.

\section{Challenges and Concerns of SaaS}

1. The cloud computing Standard for software service is completely different from conventional software services.

2. The service development of cloud computing is in need of a different approach than conventional software development life cycle. 
3. The principles have been identified for cloud services are different than conventional services.

4. The existing evaluation models are focusing only on quality attributes of Software, not the service.

5. The most current quality management approaches for SaaS services focus on the perspective of service providers. Thus, do not fully take into consideration of customer requirements.

6. Incorporate the viewpoint of customers, but often not in combination with the provider's viewpoint.

\section{RESEARCH METHODOLOGY}

Cloud Computing is having mainly three service models: Infrastructure as a service, platform as a service and Software as a Service.

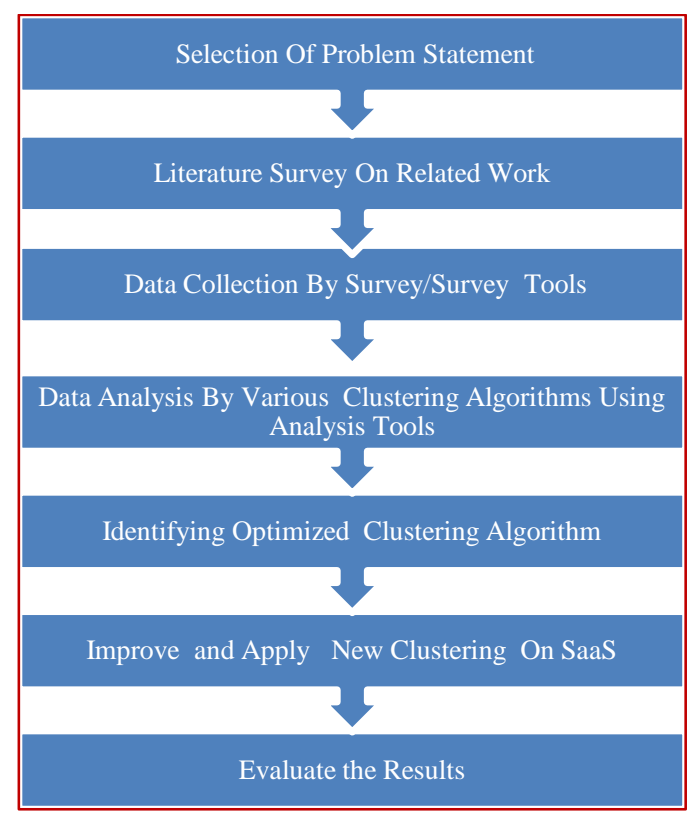

Figure 1: The Research Methodology

The Data have been collected from Amazone and stored in the following table table1.

\section{Table1: AWS data Set}

\begin{tabular}{|l|l|l|l|}
\hline ID & Name & $\begin{array}{l}\text { Product } \\
\text { Rating }\end{array}$ & $\begin{array}{l}\text { Rated } \\
\text { People }\end{array}$ \\
\hline $\mathbf{1}$ & $\begin{array}{l}\text { File Server Simple Network } \\
\text { Attached Storage provided } \\
\text { by Turnkey Linux }\end{array}$ & 4 & 4 \\
\hline $\mathbf{2}$ & $\begin{array}{l}\text { PostgreSQL Object } \\
\text { Relational Database System } \\
\text { provided by Turnkey Linux }\end{array}$ & 4 & 1 \\
\hline $\mathbf{3}$ & WSO2 App Cloud & 4 & 1 \\
\hline $\mathbf{4}$ & $\begin{array}{l}\text { Media Wiki Wikipedia's } \\
\text { Wiki Engine provided by } \\
\text { Turnkey Linux }\end{array}$ & 4 & 3 \\
\hline $\mathbf{5}$ & TYPO3 CMS 6.2 & 4 & 1 \\
\hline $\mathbf{6}$ & $\begin{array}{l}\text { Red mine Integrated SCM } \\
\text { \& Project Management } \\
\text { provided by Turnkey Linux }\end{array}$ & 4 & 3 \\
\hline $\mathbf{7}$ & Amazon Linux AMI (64bit) & 4 & 2 \\
\hline \hline $\mathbf{8}$ & Pulp Software Deployment & $\mathbf{4}$ & $\mathbf{2}$ \\
\hline
\end{tabular}

\section{IMPLEMENTATION}

Clustering is the process of grouping data into classes, or clusters, so that objects within a cluster have high similarity in comparison to one another, but are very dissimilar to objects in other clusters. The data used in the cloud computing environment are raw and unsupervised; hence it influences clustering results directly. The aim of cluster analysis is exploratory, to find if data naturally fall into meaningful groups. Clustering is a challenging field of research. The following are typical Characteristics of clustering
* Scalability
* Ability to deal with different types of attributes
* Discovery of clusters with arbitrary shape
* A minimal requirement for domain knowledge to determine input parameters
* Ability to deal with noisy data
* High dimensionality
* Constraint-based clustering
* Interpretability and usability

\section{Key Features of Software-as-a-Service}

The quality of software as a service is including quality software product plus the quality of service. The key features of SaaS are also critical in order to define a quality model of SaaS.

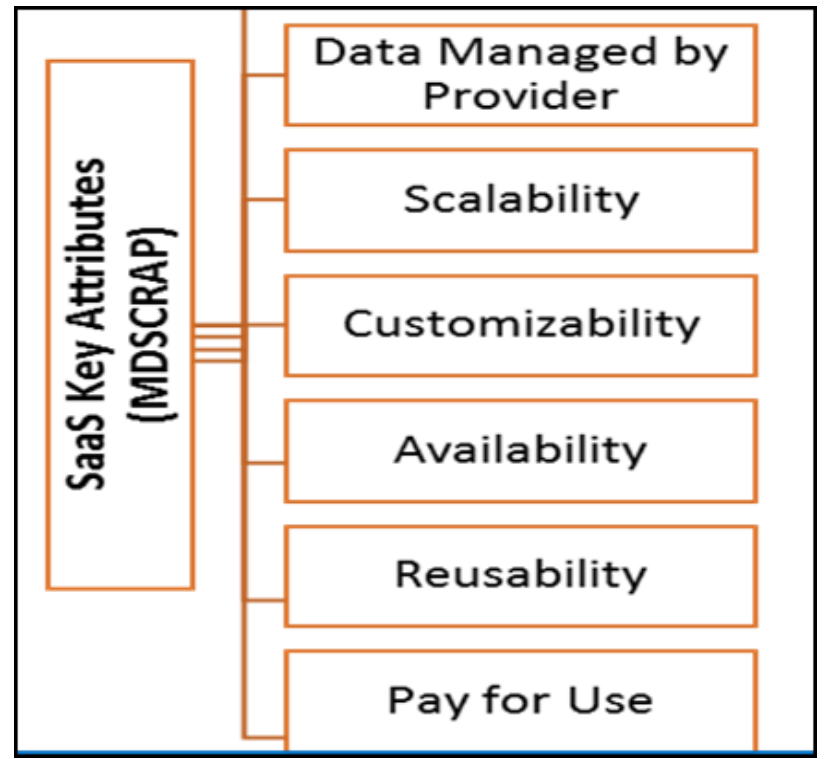

Figure 2: Key Attributes of SaaS

Welcome to rattle (rattle.togaware.com)

$\mathrm{R}$ is a free software environment for statistical computing and graphics. Together they provide sophisticated environments for data mining, statistical analyses, and data visualisation.

The rattle is a free graphical user interface for Data Mining, developed using $R$. The rattle is licensed under the GNU General Public License, Version 2. Rattle Version 4.1.0. The rattle was created and implemented by Graham Williams.

Loading AWS Data Set. 


\section{RESULT AND DISCUSSION}

The data set has been studied thoroughly and analysed and found the result is shown in the below figures.

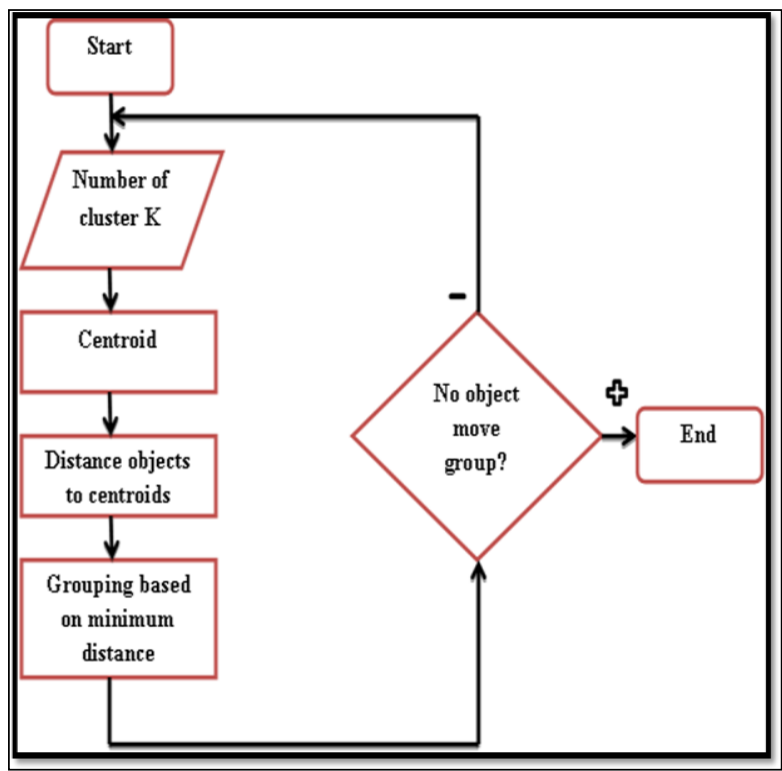

Figure 3: K-Means Clustering

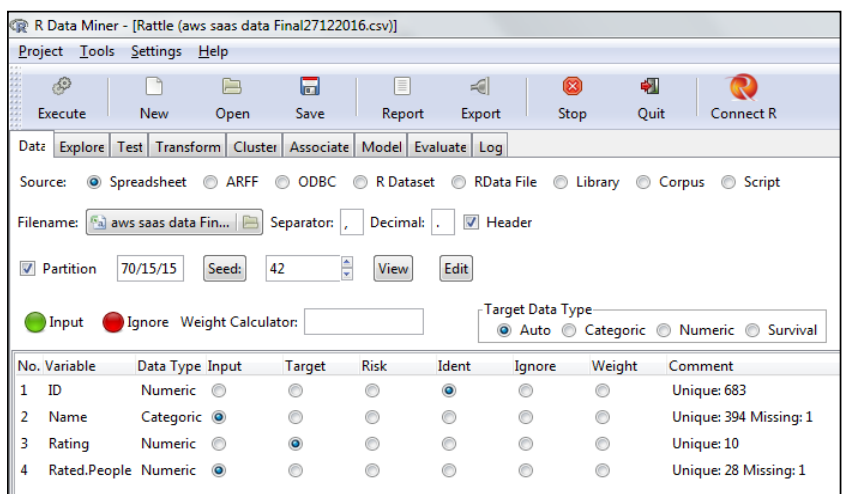

Figure 4: Loading AWS Data

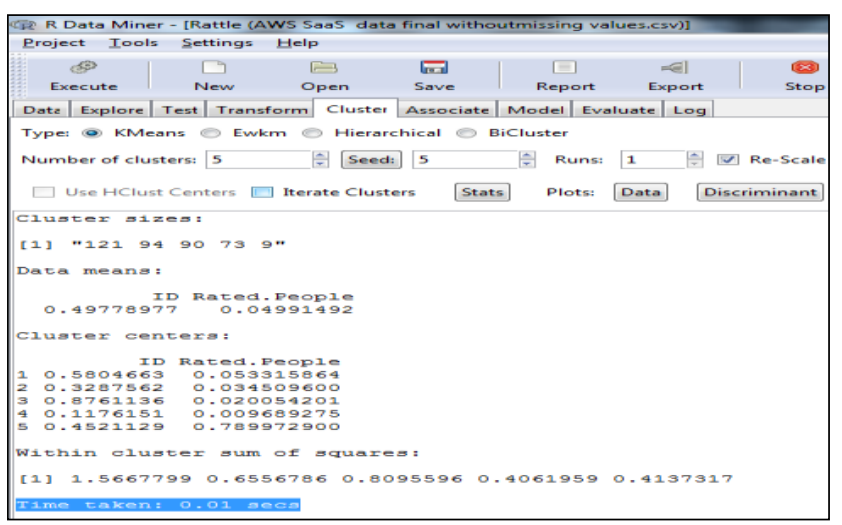

Figure 5: Analysis of K- Means Clustering

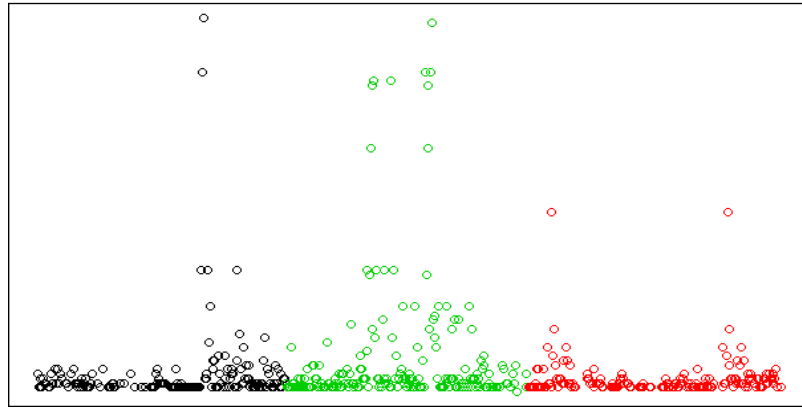

Figure 6: Results of K- Means Clustering

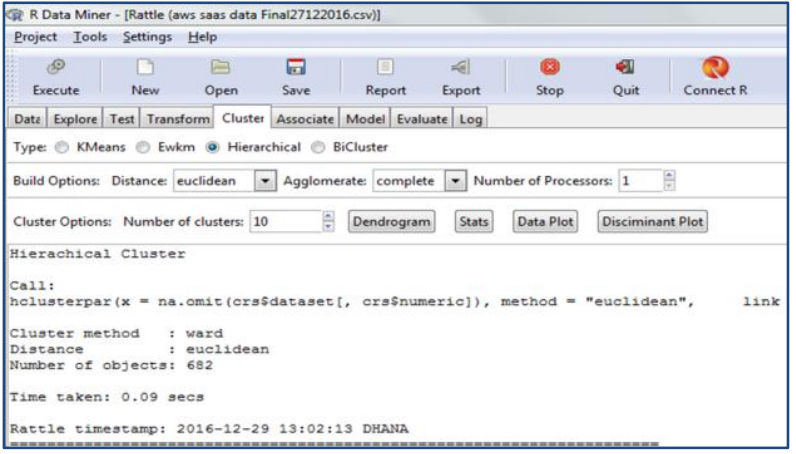

Figure 7: Analysis of AWS Data using Hierarchical Clustering

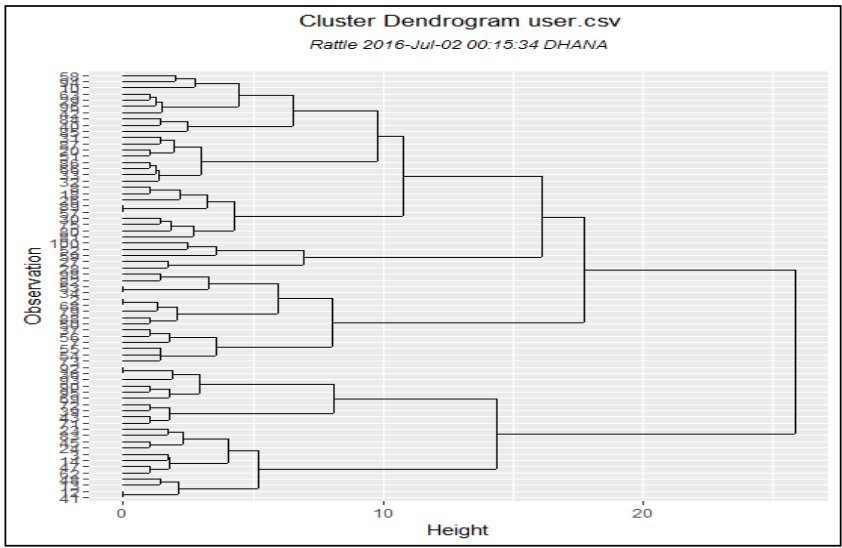

Figure 7: Results of Hierarchical Clustering

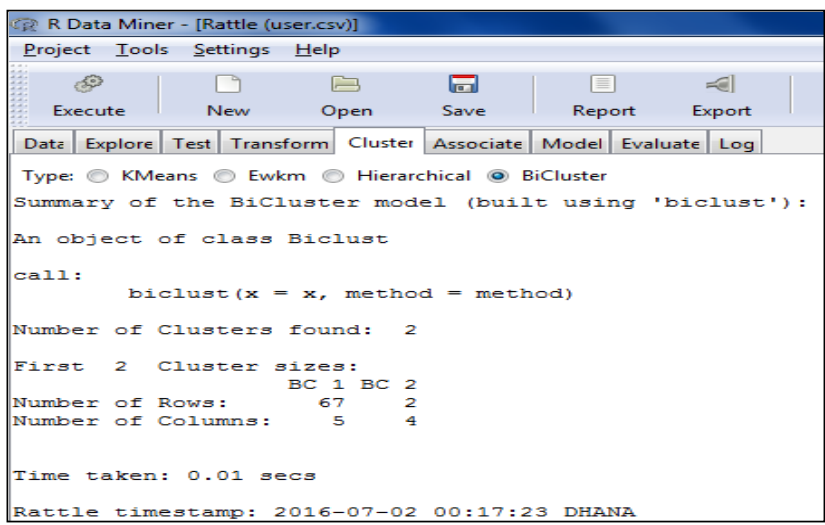

Figure 8: Analysis of AWS Data using BiCluster 
Table 2: Results Table for Response Time

\begin{tabular}{|ccc|}
\hline Reno & Name of the clustering & Time taken \\
\hline $\mathbf{1}$ & K-means & $0.07 \mathrm{Sec}$ \\
\hline $\mathbf{2}$ & Hierarchical & $0.09 \mathrm{Sec}$ \\
\hline $\mathbf{3}$ & BiCluster & $0.11 \mathrm{Sec}$ \\
\hline
\end{tabular}

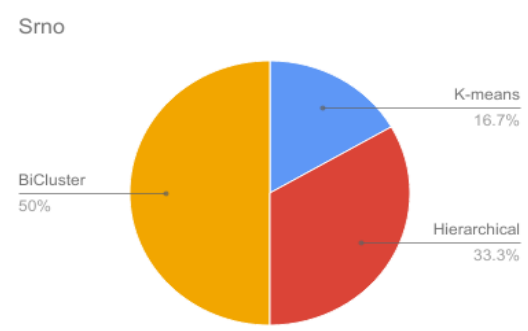

Figure 10: Result Analysis all 3 Clusters for time

\section{CONCLUSION AND FURTHER SCOPE}

In this Paper, saas evaluation of clustering methods has been studied thoroughly. The saas related data have been collected from AWS and studies and analysed by Using R Tool. The various clustering algorithms performed based on the AWS data and found that the time taken by K-Means Clustering Algorithm very less comparatively other clustering methods. It is also thought to implement new clustering algorithm which can reduce even to less time than K-Means Clustering in the Future.

\section{REFERENCES}

[1] I. Atom and C. H. Bong, "Measuring Software Quality in Use: State-of- the-Art and Research Challenges," Sop, vol. 17, no. 2, 2015.

[2] Y. Bard and G. Caplan, "Software-as-a-Service and Version log: Towards Innovative Service Differentiation," in 2010 24th IEEE International Conference on Advanced Information Networking and Applications, 2010, pp. 237-243.

[3] G. Alves, C. Silva, E. Cavalcante, T. Batista, and F. Lopes, "Relative QoS: A New Concept for Cloud Service Quality," IEEE Serv. oriented, 2015.
[4] N. Baliyan and S. Kumar, "Quality Assessment of Software as a Service on Cloud Using Fuzzy Logic," in 2013 IEEE International Conference on Cloud Computing in Emerging Markets (CCEM), 2013, pp. 16.

[5] A. Banka, A. Sarangi, M. Sain, and H. J. Lee, "Exploration of security parameters to evaluate SaaS," 2013 4th Int. Conf. Comput. Commun. Netw. Technol. ICCCNT 2013, 2013.

[6] A. K. Bardsiri and S. M. Hashemi, "QoS Metrics for Cloud Computing Services Evaluation," Int. J. Intell. Syst. Appl., vol. 6, no. 12, pp. 27-33, 2014.

[7] A. Benlian, M. Koufaris, and T. Hess, "Service Quality in Software-as-a-Service: Developing the SaaS-Qual Measure and Examining Its Role in Usage Continuance," J. Manag. Inf. Syst., vol. 28, no. 3, pp. 85-126, 2012.

[8] N. Boussoualim, "Evaluation and Selection of SaaS Product based on user preferences," pp. 299-308, 2015.

[9] F. Braithwaite and M. Woodman, "Success Dimensions in Selecting Cloud Software Services," 2011 37th EUROMICRO Conf. Softw. Eng. Adv. Appl., pp. 146154, 2011.

[10] L. Burton, "Quality of Service Attributes for Software as a Service," pp. 38-47, 2013.

[11] G. Chen, X. Bai, X. Huang, M. Li, and L. Zhou, "Evaluating services on the cloud using ontology QoS model," Proc. 2011 IEEE 6th Int. Symp. Serv. Oriented Syst., no. Some, pp. 312-317, 2011.

[12] S. W. Choi and S. D. Kim, "A quality model for evaluating reusability of services in SOA," Proc. - 10th IEEE J. Conf. E-Commerce Technol. 5th Enter. Comput. E-Commerce E-Services, CEC 2008 EEE 2008, pp. 293 298, 2008.

[13] Dhanamma Jagli, Seema. Purohit, and N. Subhash Chandra, "SAASQUAL: A Quality Model For Evaluating SaaS on The Cloud Computing Environment".

[14] Dhanamma. Jagli, Seema. Purohit, and N. S. Chandra, "Evaluating Service Customizability of SaaS on the Cloud Computing Environment," Int. J. Comput. Appl., vol. 141, no. 9, 2016. 